\title{
Antinociceptive, Anti-inflammatory and Hypoglycemic Activities of Terminalia citrina Leaves
}

\author{
Narhari Das', Md. Sharif Hasan", Sheikh Zahir Raihan ${ }^{1}$ and Md. Zakir Sultan² \\ ${ }^{1}$ Department of Clinical Pharmacy \& Pharmacology, Faculty of Pharmacy, University of Dhaka \\ Dhaka-1000, Bangladesh \\ ${ }^{2}$ Centre for Advanced Research in Sciences (CARS), University of Dhaka, Dhaka-1000, Bangladesh \\ Received: May 08, 2015; Accepted: December 03, 2015; Published (Web): February 17, 2016
}

\begin{abstract}
The present study was designed to investigate the antinociceptive, anti-inflammatory and hypoglycemic effects of petroleum ether, carbon tetrachloride, dichloromethane and ethyl acetate soluble partitionates of the methanolic extracts of Terminalia citrina leaves. The partitionates of the methanolic extract of the leaves of plant $T$. citrina at $200 \mathrm{mg} / \mathrm{kg}$ and $400 \mathrm{mg} / \mathrm{kg}$ were subjected for their antinociceptive activity using both acetic acid induced writhing method and radiant heat tail flicking method; anti-inflammatory activity was evaluated by HRBC membrane stabilization method and hypoglycemic activity by blood glucose level test. The carbon tetrachloride partitionate at $400 \mathrm{mg} / \mathrm{kg}$ induced significant decrease in the no. of writhes while the petroleum ether partitionate at $400 \mathrm{mg} / \mathrm{kg}$ showed promising activity compared to standard diclofenac sodium. Similarly, the petroleum ether partitionate elongates the reaction time significantly after administration of extract in radiant heat tail flicking method, suggesting central antinociceptive activity and at concentration of $2000 \mu \mathrm{g} / \mathrm{ml}$ showed promising protection of HRBC in hypotonic solution compared with standard naproxen. On the other hand, in hypoglycemic activity, the ethyl acetate partitionate shows significant activity compared to standard metformin drug.
\end{abstract}

Key words: Terminalia citrina, antinociceptive, anti-inflammatory, hypoglycemic

\section{Introduction}

Terminalia citrina (Bengali name: Haritaki, Family: Combretaceae) is a deciduous tree found wide spread throughout the forest of Gazipur, Tangail, Sylhet, Chittagong, Rangamati and Chittagong hill tracts in Bangladesh. It is an important medicinal plant having various ethno pharmacological uses. Different parts of the plant are used for various ailments. The fruit is used in long-term fever, loss of appetite and as sexual stimulant in Bangladesh (Hossan et al., 2008), diarrhea, helminthes and other digestive disorders in Iran (Amiri and Joharchi, 2013). Its bark is diuretic and cardio tonic (Khare, 2007). Seed is used in stomach aches and intestinal diseases (Lev and Amar, 2000). The plant is also used in asthma, diarrhea, boils, burns, constipation, migraine, dental diseases, haemoptysis,

dizziness, bleeding hemorrhoids, eye disease, gastric hyperacidity, anemia, arthritis, hoarse voice, dysentery, pyrexia, infections, traumatic cuts, cardiac diseases, cough, hepatomegaly, urolithiasis and for life longevity in Myanmar (Soe and Ngwe, 2004). A detailed literature survey revealed that seed of plant was reported to possess antioxidant properties (Palasuwan $e t$ $a l ., 2005)$ and five tannins identified as corilagin, punicalagin, 1,3,6-tri-O-galloyl- $\beta$-D-glucopyranose, chebulagic acid and 1,2,3,4,6-penta-O-galloyl- $\beta$-Dglucopyranose was isolated from methanol extract of fruit (Burapadaja and Bunchoo, 1995).

Keeping in view of this collection and utilization of different parts of $T$. citrina, an attempt was made to investigate the antinociceptive, anti-inflammatory and hypoglycemic activities of partitionates of methanolic extract of leaves of $T$. citrina.

\section{Materials and Methods}

Plant materials: The leaves of T. citrina were collected from Rangamati district, Bangladesh during the month of January 2013. The plants were mounted 
on paper and the sample was identified by the experts of Bangladesh National Herbarium, Mirpur, Dhaka (DACB, Accession Number-38094).

Extraction and fractionation: The leaves of the plant were collected in fresh condition. The dried and coarse powder (1000 gm) was extracted with methanol $(4.0 \mathrm{~L})$ in an air tight, clean flat-bottomed container for 15 days at room temperature with occasional stirring. The extract was then filtered through a fresh cotton plug followed by a Whatman No. 1 filter paper. The filtrate was concentrated using a rotary evaporator at low temperature $\left(40-45^{\circ} \mathrm{C}\right)$ and pressure. The weight of the crude extract was $50 \mathrm{gm}$. Solvent-Solvent partitioning was done using the protocol designed by Kupchan (Kupchan et al., 1973) and modified version of Wagenen (Vanwagenen et al., 1993). The crude extract (5 gm) was dissolved in 10\% aqueous methanol which was subsequently extracted first with petroleum ether (PE), then carbon tetrachloride (CTC) followed by dichloromethane (DCM) and finally with ethyl acetate (EA). All the fractions were evaporated to dryness by using rotary evaporator and kept in airtight containers for further analysis (PE $975 \mathrm{mg}$, CTC $835 \mathrm{mg}$, DCM $640 \mathrm{mg}$ and EA $590 \mathrm{mg}$ ).

Chemicals and reagents: Diclofenac, Morphine and Metformin were collected from ACI Pharmaceuticals, Popular Pharmaceuticals and Square Pharmaceuticals Ltd., Dhaka, Bangladesh respectively. Acetic acid was obtained from Merck, Germany. All others chemicals were obtained commercially and were of analytical grade.

Experimental animals: Swiss-albino mice (20-25 gm) of either sex, aged 4-5 weeks obtained from the Animal Resource Branch of Jahangirnagar University, Dhaka, Bangladesh were used for the experiment. They were kept in standard environmental condition and fed standard formulated rodent food and water. All experimental protocols were approved by the University of Dhaka, Faculty of Pharmacy Ethics Committee.

\section{Antinociceptive study}

Effect on acetic acid-induced writhing in mice: Antinociceptive activity was evaluated by the acetic acid induced writhing method in mice (Hossain et al.,
2013). The writhes were induced by intra-peritoneal injection of $0.7 \%$ acetic acid (v/v) $(10 \mathrm{ml} / \mathrm{kg})$. Two different doses (200 and $400 \mathrm{mg} / \mathrm{kg}$ ) of the extract were administered orally to different groups of 5 animals each, $30 \mathrm{~min}$ before chemical stimulus. The number of writhes during the following $15 \mathrm{~min}$ period was observed after acetic acid injection. Antinociception was expressed as the reduction of the number of abdominal constrictions between control animals (acetic acid treated mice) and mice pretreated with the extract. Diclofenac sodium (50 mg/ kg, i.p.) was used as standard.

Effect of Tail flicking in mice: Antinociceptive activity was evaluated by radiant heat tail flicking method (Goshwami et al., 2012). Test samples and control was given orally by means of a feeding needle to the mice at zero hour. A 30 min interval was given to ensure proper absorption of the administered substances. After $30 \mathrm{~min}$, the tail flicking time was measured by analgesiometer (Medicraft, India). Morphine ( $2 \mathrm{mg} / \mathrm{kg}$, s.c.) was used as standard. The strength of the current passing through the naked nicrome wire was kept constant at 3 Amps. The tail skin was kept at a distance of $1.5 \mathrm{~cm}$ from the heat source. Radiant heat $\left(55 \pm 2{ }^{\circ} \mathrm{C}\right)$ in the tail was applied and maintained at $2.5 \mathrm{~cm}$ measured from the root of the tail. In order to avoid the tissue damage, the cut of reaction time was kept at $16 \mathrm{sec}$.

\section{In vitro anti inflammatory activity}

Preparation of red blood cells: Human blood was collected from a donor not consuming any NSAID drugs for two weeks. The blood was subjected to centrifugation and the supernatant part was carefully pipetted out with sterile pipettes. The packed cells were resuspended with equal volume of normal physiological saline ( $\mathrm{pH}$ 7.4) and centrifuged again. The process was repeated five times until the supernatants were clear. A $10 \%$ HRBC suspension was then prepared with normal physiological saline and used immediately (Oyedapo and Famurewa, 1995).

Membrane stabilizing activity assay: $4.5 \mathrm{ml}$ of reaction mixture consisting of $2 \mathrm{ml}$ hypotonic saline $(0.25 \% \mathrm{w} / \mathrm{v} \mathrm{NaCl}), 1 \mathrm{ml}$ of sodium phosphate buffer $(0.15 \mathrm{M}, \mathrm{pH} 7.4)$ and $1 \mathrm{ml}$ of extract were dissolved in 
normal physiological saline. Then $0.5 \mathrm{ml}$ of $10 \%$ HRBC was also added. Two controls were performed, one with $1.0 \mathrm{ml}$ of isotonic saline instead of extract, and the second control with $0.5 \mathrm{ml}$ of isotonic saline instead of red blood cells. The mixture was incubated at $56{ }^{\circ} \mathrm{C}$ for $30 \mathrm{~min}$. The tubes were cooled under running water for $20 \mathrm{~min}$ and the mixture was centrifuged at 3000 rpm. The supernatants were separated and the absorbance of the supernatants was noted at $560 \mathrm{~nm}$. The percentage membrane stabilizing activity was determined using the equation shown below (Gadamsetty et al., 2013). Naproxen was used as standard.

$\%$ of Membrane stability $=100-($ Abs. of drug sample - Abs. of drug control) x $100 /$ (Abs. of blood control)

Blood control represented $100 \%$ lysis or zero percent stability.

Hypoglycemic activity: The test is performed using a slight modification (Shahreen et al., 2011). The animals were fasted for $12 \mathrm{~h}$, weighed and randomly divided into ten groups consisting of 6 mice in each group. At zero hour fasting blood glucose level from each group was measured from tail vein just prior to glucose administration by using glucometer (Ez Smart168) and glucose oxidase-peroxidase reactive strips. To measure the blood glucose level, tail tip of mice was cut with a sharp blade and little amount of blood was collected and exposed to touch glucose test strips. Within seconds blood glucose level was visualized. Nebanol (Bacitracin) ointment was applied on the wound to avoid infection. Then, the samples were administered $(0.1 \%$ saline for control, metformin for standard and extracts) using oral feeding needle. After 1 hour, 2 hours and 3 hours, blood sample were collected in the same procedure and blood glucose level measured to see the hypoglycemic effect of the test sample in relative to control and standard groups.

Statistical analysis: All values were expressed as the mean \pm standard error of the mean (SEM) and the results were analyzed statistically by one way analysis of variance (ANOVA) followed by Dunnett's t-test by using SPSS Ver.16. $\mathrm{P}<0.05$ compared to standard was considered to be statistically significant.

\section{Results and Discussion}

Natural products derived from plants have been used in folklore medicine to treat different diseases. So with the objective to contribute to the knowledge of the medicinal flora and considering the use of this plant, a pharmacological study of the antinociceptive, antiinflammatory and hypoglycemic effects of petroleum ether, carbon tetrachloride, dichloromethane and ethyl acetate soluble partitionates of methanolic extracts of $T$. citrina leaves was done. To our knowledge, this is the first time that the antinociceptive, in vitro membrane stabilizing property and hypoglycemic activities in experimental models are reported. The results are summarized in the tables 1-4.

The partitionates antinociceptive activity was demonstrated using two classical in vivo models. On the one hand, the partitionates showed a significant antiinflammatory activity in vitro HRBC membrane stabilizing model. Similarly, T. citrina partitionates were found to have hypoglycemic activity.

In acetic acid induced writhing method, it was observed that there was a dose dependent reduction in the number of writhes in the test animals. The partitionates effectively reduced the number of abdominal muscle contractions induced by $0.7 \%$ acetic acid solution in a dose dependent manner (Ttable 1). The carbon tetrachloride fraction $(400 \mathrm{mg} / \mathrm{kg} \mathrm{b.w.)}$ of $T$. citrina showed significant antinociceptive activity having $37.49 \%$ of inhibition compared to the standard diclofenac $(55.14 \%)$. The petroleum ether fraction of methanolic extract (400 mg/kg b.w.) showed promising antinociceptive activity having $25.00 \%$ of inhibition of writhings whereas dichloromethane fraction showed least inhibition of writhings. Acetic acid-induced abdominal writhing model represents pain sensation by releasing arachidonic acid via cyclooxygenase and prostaglandin biosynthesis which plays a role in the nociceptive mechanism (Adedapo et al., 2009). Prostanoids such as PGE2 and PGF2 $\alpha$ as well as lipoxygenase products have been found at higher level in the peritoneal fluid after intraperitonial injection of acetic acid. The antinociceptive effect occurs due to its action on visceral receptors that is sensitive to acetic acid by inhibiting the production of algogenic substances or inhibiting the transmission of painful 
messages at the central level (Sekhar et al., 2014). The acetic acid induced writhing response is a sensitive method to evaluate peripherally acting antinociceptive activity. Thus, the reduction in the number of writhing indicates that extract might exert antinociceptive activity by inhibition of prostaglandin synthesis or action of prostaglandins.

Table 1. Effect of oral administration of extract on acetic acid induced writhing in mice.

\begin{tabular}{lcl}
\hline Group & $\begin{array}{c}\text { Number of writhing } \\
(\text { Mean } \pm \text { SEM) }\end{array}$ & $\begin{array}{l}\text { Inhibition of } \\
\text { writhing }(\%)\end{array}$ \\
\hline Control & $27.2 \pm 1.06$ & ND \\
Standard $(50 \mathrm{mg} / \mathrm{kg})$ & $12.2 \pm 0.86^{* * *}$ & 55.14 \\
PET $(200 \mathrm{mg} / \mathrm{kg})$ & $23 \pm 0.70^{*}$ & 15.44 \\
PET $(400 \mathrm{mg} / \mathrm{kg})$ & $20.4 \pm 0.92^{* * *}$ & 25.00 \\
CT $(200 \mathrm{mg} / \mathrm{kg})$ & $22 \pm 0.70^{* *}$ & 19.11 \\
CT $(400 \mathrm{mg} / \mathrm{kg})$ & $17 \pm 0.70^{* * *}$ & 37.49 \\
DCM $(200 \mathrm{mg} / \mathrm{kg})$ & $25 \pm 0.70$ & 8.08 \\
DCM $(400 \mathrm{mg} / \mathrm{kg})$ & $23.2 \pm 0.86^{*}$ & 17.7 \\
\hline EA $(200 \mathrm{mg} / \mathrm{kg})$ & $22.6 \pm 0.92^{* *}$ & 16.91 \\
EA $(400 \mathrm{mg} / \mathrm{kg})$ & $21.2 \pm 0.86^{* * *}$ & 22.05
\end{tabular}

Each value represents Mean \pm SEM. $* * * \mathrm{P}<0.001, * * \mathrm{P}<0.01$, $* \mathrm{P}<$ 0.05 compared with control. (One way ANOVA followed by Dunnett's t-test). SEM= Standard Error of Mean; Standard= Diclofenac Sodium; PET = Petroleum ether soluble fraction; $\mathrm{CT}=$ Carbon tetrachloride soluble fraction; $\mathrm{DCM}=$ Dichloromethane soluble fraction; $\mathrm{EA}=$ Ethyl acetate soluble fraction. $\mathrm{ND}=$ Not Determined.

In the tail-flick model, reaction time was increased significantly for the test samples and standard drug when compared to the predrug reaction time (control group) of $30 \mathrm{~min}$ after drug administration (Table 2). The carbon tetrachloride fraction $(400 \mathrm{mg} / \mathrm{kg} \mathrm{b.w.})$ of T. citrina showed significant antinociceptive activity having $32.89 \%(\mathrm{P}<0.05)$ elongation of reaction time 30 minutes after administration of sample compared to the standard morphine $(136.48 \%)$. The ethyl acetate fraction of methanolic extract $(400 \mathrm{mg} / \mathrm{kg}$ b.w.) showed promising antinociceptive activity having $29.64 \%$ elongation of reaction time whereas dichloromethane fraction showed least elongation of reaction time $(17.58 \%)$. The tail-flick test are considered to be selective to examine compounds acting through opioid receptor, the extract increased mean basal latency time which indicates that it may act via centrally mediated antinociceptive mechanism (Vogel, 2008). Narcotic antinociceptive inhibit both peripheral and central mechanism of pain, while non steroidal antiinflammatory drugs inhibit only peripheral pain. The extract exhibited inhibition of both mechanisms of pain, suggesting that the plant extract may act as a narcotic antinociceptive. It has been reported that tannins and alkaloids have ability to inhibit pain perception (Hossain et al., 2013). So these phyto-constituents might be responsible for the antinociceptive activity.

It is evident that the partitionates of methanolic extract protected the human erythrocyte membrane against lysis induced by hypotonic solution. The results are shown in table 3. The partitionates showed significant anti-inflammatory activity in a concentration dependent manner. The petroleum ether partitionate at a concentration of $2000 \mu \mathrm{g} / \mathrm{ml}$ showed highest $61.60 \%$ protection of HRBC in hypotonic solution compared with standard naproxen which showed $73.21 \%$ protection while ethyl acetate partitionate showed least protection of HRBC. The erythrocyte membrane may be considered a model of the lysosomal membrane which plays an important role in inflammation (Kumbhare et al., 2013). The compounds which prevent the lysis of membrane caused by the release of hydrolytic enzymes contained within the lysosomes may relieve some symptoms of inflammation (Gadamsetty et al., 2013). When the human RBC is subjected to hypotonic stress, the hemoglobin release from RBC will be prevented by anti-inflammatory drugs because of the membrane stabilization. It has been demonstrated that certain herbal preparations were capable of stabilizing the red blood cell membrane and this may be indicative of their ability to exert antiinflammatory activity (Kumbhare et al., 2013). The mode of action of the extracts or drugs, may bind to the erythrocyte membranes with subsequent alteration of the surface charges of the cells. 
Table 2. Assessment of central antinociceptive activity by tail flick method.

\begin{tabular}{llll}
\hline Group & & Reaction time $(\mathrm{sec})$ & \\
& $30 \mathrm{~min}$ & $60 \mathrm{~min}$ & $90 \mathrm{~min}$ \\
& $(\%$ elongation$)$ & $(\%$ elongation $)$ & (\% elongation) \\
\hline Control & $6.14 \pm 0.59$ & $6.2 \pm 0.40$ & $6.42 \pm 0.28$ \\
Standard $(2 \mathrm{mg} / \mathrm{kg})$ & $14.52 \pm 0.49^{* * *}$ & $13.3 \pm 0.44^{* * *}$ & $11.4 \pm 0.4^{* * *}$ \\
& $(136.48)$ & $(114.51)$ & $(77.57)$ \\
PET $(200 \mathrm{mg} / \mathrm{kg})$ & $5.46 \pm 0.46$ & $5.44 \pm 0.42$ & $5.72 \pm 0.35$ \\
& $(11.07)$ & $(12.25)$ & $(10.9)$ \\
PET $(400 \mathrm{mg} / \mathrm{kg})$ & $7.76 \pm 0.46$ & $8.54 \pm 0.63^{* *}$ & $8.88 \pm 0.60^{* *}$ \\
& $(26.38)$ & $(37.74)$ & $(38.31)$ \\
CT $(200 \mathrm{mg} / \mathrm{kg})$ & $6.44 \pm 0.46$ & $6.72 \pm 0.31$ & $6.96 \pm 0.31$ \\
& $(4.88)$ & $(8.38)$ & $(8.41)$ \\
CT $(400 \mathrm{mg} / \mathrm{kg})$ & $8.16 \pm 0.43^{*}$ & $8.44 \pm 0.52^{* *}$ & $8.24 \pm 0.39 *$ \\
& $(32.89)$ & $(36.12)$ & $(28.34)$ \\
DCM $(200 \mathrm{mg} / \mathrm{kg})$ & $5.38 \pm 0.27$ & $5.8 \pm 0.32$ & $5.8 \pm 0.22$ \\
& $(12.37)$ & $(6.45)$ & $(9.65)$ \\
DCM $(400 \mathrm{mg} / \mathrm{kg})$ & $5.06 \pm 0.40$ & $4.90 \pm 0.51$ & $4.90 \pm 0.56$ \\
& $(17.58)$ & $(20.96)$ & $(23.67)$ \\
EA $(200 \mathrm{mg} / \mathrm{kg})$ & $6.28 \pm 0.34$ & $6.34 \pm 0.17$ & $6.54 \pm 0.24$ \\
EA $(400 \mathrm{mg} / \mathrm{kg})$ & $(2.28)$ & $(2.25)$ & $(1.86)$ \\
& $7.96 \pm 0.53^{*}$ & $8.16 \pm 0.48^{*}$ & $8.5 \pm 0.53^{*}$ \\
& $(29.64)$ & $(31.61)$ & $(32.39)$ \\
\hline
\end{tabular}

Each value represents Mean $\pm \mathrm{SEM}$. $* * * \mathrm{P}<0.001$, **P $<0.01$, $* \mathrm{P}<0.05$ compared with control. (One way ANOVA followed by Dunnett's t-test). SEM= Standard Error of Mean; Standard= Morphine; PET= Petroleum ether soluble fraction; CT= Carbon tetrachloride soluble fraction; DCM= Dichloromethane soluble fraction; EA= Ethyl acetate soluble fraction.

Table 3. Screening of in vitro evaluation of anti-inflammatory activity.

\begin{tabular}{lccc}
\hline Test sample & $\begin{array}{c}\text { Concentration } \\
(\mu \mathrm{g} / \mathrm{ml})\end{array}$ & $\begin{array}{c}\text { Absorbance } \\
(560 \mathrm{~nm})\end{array}$ & $\begin{array}{c}\text { Protection } \\
(\%)\end{array}$ \\
\hline Control & ----- & $0.112 \pm 0.001$ & ----- \\
Standard & 100 & $0.093 \pm 0.001^{*}$ & 68.75 \\
& 1000 & $0.092 \pm 0.001^{*}$ & 69.64 \\
PET & 2000 & $0.088 \pm 0.001^{*}$ & 73.21 \\
& 100 & $0.119 \pm 0.001^{*}$ & 45.53 \\
CT & 1000 & $0.117 \pm 0.001^{*}$ & 47.32 \\
& 2000 & $0.101 \pm 0.001^{*}$ & 61.60 \\
& 100 & $0.126 \pm 0.001^{*}$ & 39.28 \\
DCM & 1000 & $0.121 \pm 0.001^{*}$ & 43.75 \\
& 2000 & $0.102 \pm 0.001^{*}$ & 60.71 \\
& 100 & $0.135 \pm 0.001^{*}$ & 31.25 \\
EA & 1000 & $0.122 \pm 0.001^{*}$ & 42.85 \\
& 2000 & $0.105 \pm 0.001^{*}$ & 58.03 \\
& 100 & $0.133 \pm 0.001^{*}$ & 33.03 \\
\hline
\end{tabular}

Each value represents Mean \pm SEM. *P<0.001 compared with control (One way ANOVA followed by Dunnett's t-test). SEM= Standard Error of Mean; Standard= Naproxen; PET= Petroleum ether soluble fraction; CT= Carbon tetrachloride soluble fraction; $\mathrm{DCM}=$ Dichloromethane soluble fraction; $\mathrm{EA}=$ Ethyl acetate soluble fraction. 
Table 4. Effects of extracts of $T$. citrina on blood glucose level induced in mice.

\begin{tabular}{lllll}
\hline Group & \multicolumn{4}{l}{ Level of glucose (Mean \pm SEM) } \\
\cline { 2 - 5 } & 0 hour & 1 hour & 2 hours & 3 hours \\
\hline Control & $5.98 \pm 0.28$ & $6 \pm 0.15$ & $5.9 \pm 0.19$ & $5.75 \pm 0.17$ \\
Standard & $6.05 \pm 0.18$ & $3.78 \pm 0.13^{* * *}$ & $3.6 \pm 0.15^{* * *}$ & $3.43 \pm 0.11^{* * *}$ \\
PET $(200 \mathrm{mg} / \mathrm{kg})$ & $6.08 \pm 0.25$ & $5.46 \pm 0.16$ & $5.15 \pm 0.06^{*}$ & $5.15 \pm 0.07$ \\
PET $(400 \mathrm{mg} / \mathrm{kg})$ & $6.13 \pm 0.22$ & $5.86 \pm 0.22$ & $5.55 \pm 0.28$ & $5.33 \pm 0.24$ \\
CT $(200 \mathrm{mg} / \mathrm{kg})$ & $5.88 \pm 0.11$ & $5.95 \pm 0.16$ & $5.96 \pm 0.21$ & $5.96 \pm 0.14$ \\
CT $(400 \mathrm{mg} / \mathrm{kg})$ & $6.07 \pm 0.25$ & $5.65 \pm 0.25$ & $5.31 \pm 0.21$ & $5.13 \pm 0.20$ \\
DC $(200 \mathrm{mg} / \mathrm{kg})$ & $6.08 \pm 0.19$ & $6.00 \pm 0.19$ & $5.91 \pm 0.18$ & $5.81 \pm 0.15$ \\
DC $(400 \mathrm{mg} / \mathrm{kg})$ & $6.00 \pm 0.15$ & $5.98 \pm 0.29$ & $5.75 \pm 0.17$ & $5.43 \pm 0.19$ \\
EA $(200 \mathrm{mg} / \mathrm{kg})$ & $5.95 \pm 0.14$ & $5.05 \pm 0.27 *$ & $4.73 \pm 0.28^{* *}$ & $4.55 \pm 0.21^{* * *}$ \\
EA $(400 \mathrm{mg} / \mathrm{kg})$ & $5.71 \pm 0.13$ & $5.00 \pm 0.19 *$ & $4.68 \pm 0.22 * *$ & $4.41 \pm 0.19 * * *$ \\
\hline
\end{tabular}

Each value represents the mean \pm SEM $(\mathrm{n}=6)$. $* * * \mathrm{P}<0.001$, ** $\mathrm{P}<0.01, * \mathrm{P}<0.05$ compared with control (One way ANOVA followed by Dunnett's test). SEM= Standard Error of Mean; Standard= Metformin; PET= Petroleum ether soluble fraction; CT= Carbon tetrachloride soluble fraction; DC $=$ Dichloromethane soluble fraction; EA= Ethyl acetate soluble fraction.

The results of hypoglycemic test indicated that the partitionates suppressed the rise in blood glucose level after administration of extract. The results are shown in table 4. The ethyl acetate partitionate of $T$. citrina has significant blood glucose lowering activity at the doses of $200 \mathrm{mg} / \mathrm{kg}$ and $400 \mathrm{mg} / \mathrm{kg}$ body weight. After 1 hour, the plasma glucose level at doses $200 \mathrm{mg} / \mathrm{kg}$ and $400 \mathrm{mg} / \mathrm{kg}$ were $5.05 \pm 0.27 \mathrm{mmol} / \mathrm{L}(\mathrm{P}<0.05)$ and 5.00 $\pm 0.19 \mathrm{mmol} / \mathrm{L}(\mathrm{P}<0.05)$. The outcome may be due to the enhancement of gluconeo-genesis, which is characteristically activated at fasting state in diabetic animals or increase disposal of glucose by enhanced insulin sensitivity (Jahan et al., 2009).

\section{Conclusion}

From these investigations it may be concluded that the various partitionates of methanolic extracts of $T$. citrina showed significant antinociceptive, in vitro antiinflammatory effects. However, further investigations are required in the laboratory to isolate and characterize the specific active components of the plant extract which is responsible for observed pharmacological actions.

\section{Acknowledgements}

The authors would like to acknowledge Head of the Department of Clinical Pharmacy and Pharmacology, Faculty of Pharmacy and Centre for
Advanced Research in Sciences (CARS), University of Dhaka, Dhaka-1000, Bangladesh for providing chemicals, laboratory facility and moral support to carry out this research.

\section{Conflict of interest}

We declare that we have no conflict of interest.

\section{References}

Adedapo, A.A., Sofidiya, M.O. and Afolayan, A.J. 2009. Anti-inflammatory and analgesic activities of the aqueous extracts of Margaritaria discoidea (Euphorbiaceae) stem bark in experimental animal models. Rev. Biol. Trop. 57, 1193-1200.

Amiri, M.S. and Joharchi, M.R. 2013. Ethnobotanical investigation of traditional medicinal plants commercialized in the markets of Mashhad, Iran. Avicenna J. Phytomed. 3, 254-271.

Burapadaja, S. and Bunchoo, A. 1995. Antimicrobial activity of tannins from Terminalia citrina. Planta Med. 61, 365366.

Gadamsetty, G., Maru, S., Tyagi, A. and Chakravarthula, S.A. 2013. Anti-inflammatory, cytotoxic and antioxidant effects of methanolic extracts of Drypetes sepiaria (Euphorbiaceae). Afr. J. Tradit. Complement. Altern. Med. 10, 274-282.

Goshwami, D., Rahman, M.M., Muhit, M.A. and Islam, M.S. 2012. Antinociceptive activity of leaves of Lasia spinosa. Arch Appl. Sci. Res. 4, 2431-2434. 
Hossain, H., Jahan, I.R., Howlader, S.I., Dey, S.K., Hira, A. and Ahmed, A. 2013. Phytochemical screening and antinociceptive properties of the ethanolic leaf extract of Trema Cannabina Lour. Adv. Pharma. Bull. 3, 103-108.

Hossan, M.S., Hanif, A., Khan, M., Bari, S., Jahan, R. and Rahmatullah, M. 2008. Ethnobotanical survey of the Tripura tribe of Bangladesh. American Eurasian $J$. Sustainable Agri. 3, 253-261.

Jahan, S., Saeed, N., Ijlal, F., Khan, M.A., Ahmad, M., Zafar, M. and Abbasi, A.M. 2009. Histomorphological study to evaluate anti-fertility effect of Abrus precatories L. in adult male mice. J. Med. Plants Res. 3, 1021-1028.

Khare, C.P. 2007. Indian Medicinal Plants, an Illustrated Dictionary, Springer-Versa Berlin/Heidelberg; 654.

Kumbhare, M.R., Sivakumar, T., Morankar, P.G. and Kalantri, M. 2013. Membrane stabilizing potential and antimicrobial activity of the Pods of Caesalpinia Pulcherrima (Caesalpiniaceae) against selected microbes. Indo. American J. Pharma. Res. 3, 3472-3480.

Kupchan, S.M., Britton, R.W., Ziegler, M.F. and Sigel, C.W. 1973. Bruceantin, a new potent antileukemic simaroubolide from Brucea antidysenterica. J. Org. Chem. 38, 178-179.

Lev, E. and Amar, Z. 2000. Ethnopharmacological survey of traditional drugs sold in Israel at the end of the 20th century. J. Ethnopharmacol. 72, 191-205.
Oyedapo, O.O. and Famurewa, A.J. 1995. Antiprotease and membrane stabilizing activities of extracts of Fagara zanthoxyloides, Olax subscorpioides and Tetrapleura tetraptera. Int. J. Pharmacogn. 33, 65-69.

Palasuwan, A., Soogarun, S., Lertlum, T., Pradniwat, P. and Wiwanitkit, V. 2005. Inhibition of Heinz Body induction in an in vitro model and total antioxidant activity of medicinal Thai plants. Asian Pacific J. Cancer Prev. 6, 458-463.

Sekhar, N.C., Jayasree, T., Ubedulla, S., Dixit, R., Manohar, V.S. and Shankar, J. 2014. Evaluation of antinociceptive activity of aqueous extract of bark of Psidium Guajava in albino rats and albino mice. J. Clinical Diagnostic Res. 8, HF01-HF04.

Soe, K. and Ngwe, T.M. 2004. Medicinal Plants of Myanmar, Combretaceae, Forest Resource Environment Development and Conservation Association (FREDA); Series-1.

Vanwagenen, B.C., Larsen, R., Cardellina, J.H., Randazzo, D., Lidert, Z.C. and Swithenbank, C. 1993. Ulosantoin, a potent insecticide from the sponge Ulosa ruetzleri. $J$. Org. Chem. 58, 335-337.

Vogel, H.G. 2008. Analgesic, Anti-Inflammatory, and AntiPyretic Activity. Drug Discovery and Evaluation: Pharmacological Assays, 3rd ed. Springer-Verlag Berlin Heidelberg New York; pp. 983-1113. 